\title{
An IMM-GLR Approach for Marine Gas Turbine Gas Path Fault Diagnosis
}

\author{
Qingcai Yang, Shuying Li, and Yunpeng Cao $\mathbb{D}$ \\ College of Power and Energy Engineering, Harbin Engineering University, Harbin 150001, China \\ Correspondence should be addressed to Yunpeng Cao; caoyunpeng@hrbeu.edu.cn
}

Received 16 April 2018; Accepted 3 September 2018; Published 18 September 2018

Academic Editor: Luis Martínez

Copyright (C) 2018 Qingcai Yang et al. This is an open access article distributed under the Creative Commons Attribution License, which permits unrestricted use, distribution, and reproduction in any medium, provided the original work is properly cited.

\begin{abstract}
An IMM-GLR approach based on interacting multiple model (IMM) and generalized likelihood ratio (GLR) estimation was developed to detect, isolate, and estimate gas turbine gas path fault (including abrupt fault and multiple faults) in the underdetermine estimation conditions. In this approach, a model set representing gas turbine health condition and different fault condition was established, and a corresponding bank of filters was designed. An IMM-based FDI algorithm based on these filters is applied to detect and isolate fault, and a GLR estimation algorithm is used to estimate the fault severity. Then a model set update strategy based on the diagnosed fault was proposed to enable the diagnosis of multiple faults. Several simulation case studies on a marine gas turbine were conducted, and the results show that the IMM-GLR approach not only accurately diagnoses the abrupt gas path fault and multiple gas path faults but also accurately estimates the severity of the detected fault in the underdetermine estimation conditions.
\end{abstract}

\section{Introduction}

With increasing complexity of gas turbine, the requirement for reliability and security is growing significantly and the fault diagnosis is becoming a major issue in safety critical component such as gas path component. The main causes of component fault include fouling, erosion, corrosion, and foreign object damage (FOD). These causes will result in gas turbine performance degradation, further reduce its safety and stability, and lead to decreased fuel economy as well as increasing the operation cost. Gas path fault diagnosis can detect and isolate possible fault and estimate the fault severity and then help to develop a reasonable maintenance plan and reduce maintenance costs and time [1].

Various gas path fault diagnosis approaches have been developed and even applied to practice and achieve good results. Based on the available knowledge of the gas turbine, these approaches can be mainly divided into three categories, namely, model based $[2,3]$, data-driven $[4,5]$, and expert system $[6,7]$. A detailed review of these approaches can be found in [8-10]. Among them, the model based approach has received extensive attention due to its good theoretical basis. Model based approach is an analytical redundancy approach and diagnoses the fault based on residual signal, which is the difference between the observer and the gas turbine's mathematical model. And the most common approach for residual generation is parameter estimation approach. A variety of parameter estimation approaches have been developed, such as Kalman filter and its derivative approach $[2,3,11]$ and particle filter approach [12].

Gas turbine gas path fault usually cannot be directly diagnosed through the measurement parameters. Instead, these parameters are used to estimate the changes in component performance parameters (such as mass flow and isentropic efficiency) caused by gas path fault and then determine the occurring fault by the performance parameters. Most of the estimation approaches are developed based on the assumption that the number of sensors is not less than the number of performance parameters. However, due to the complexity of gas turbine and the consideration of the installation cost and difficulty of the sensors, the number of sensors in gas path component is less than the number of the performance parameters and presenting an underdetermine estimation problem [13]. A common approach to address this shortcoming is to estimate a subset of performance parameters, while it can result in "smearing" the effects of unestimated parameters 


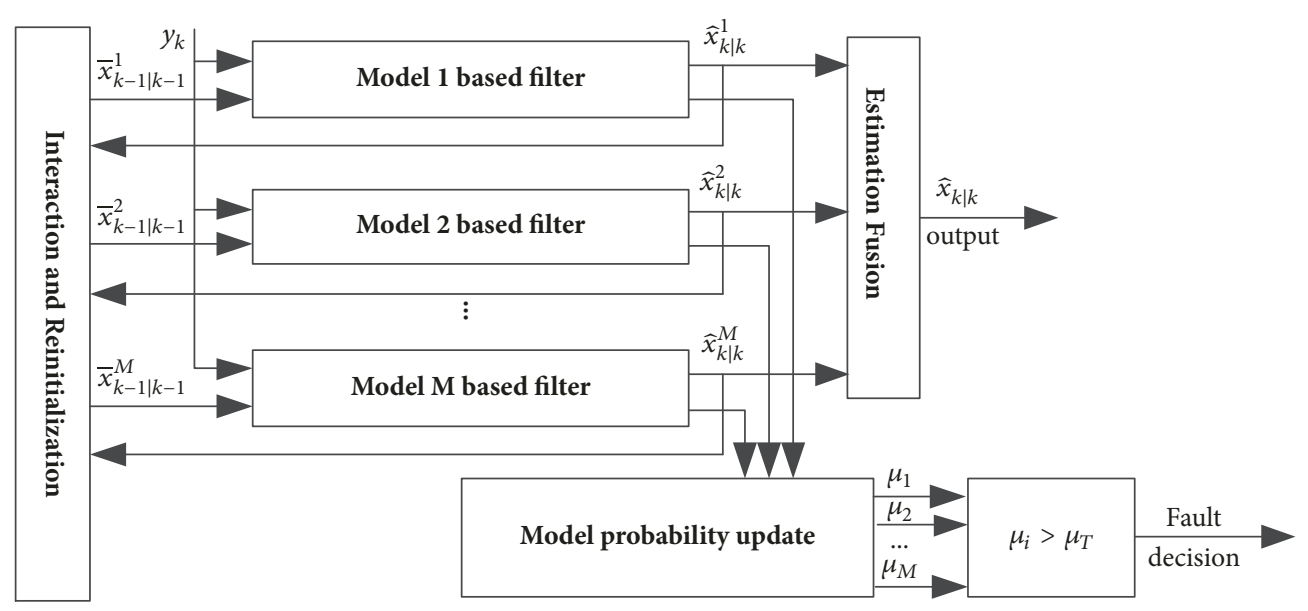

FIGURE 1: Diagram of the IMM-based FDI algorithm.

onto those which are estimated and in turn introduce error of the estimated results [2].

Considering that the occurrence of a gas path fault only caused changes in few of performance parameters, a multiple model (MM) based diagnosis approach is developed. This kind of approach does not directly estimate the performance parameters; instead, it establishes a set of hypothetical models that represent the different conditions (including health and different fault conditions) of the gas turbine and design a bank of Kalman filters corresponding to these models and then analyzes the residual of these filters to diagnose the occurring fault [14]. The MM approach is pioneered by Magill [15] and widely applied and promoted by researches [16-18]. So far, the MM approach has been identified three generations, including autonomous MM (AMM), interacting MM (IMM), and variable structure MM (VSMM); a detailed description of these approaches can be found in the literature [18].

In [14], the MM-based diagnosis approach is used for the first time to detect and isolate the gas path fault of gas turbine. And a modular and a hierarchical architecture is developed which enables the detection and isolation of both single faults as well as multiple concurrent faults in the jet engine. In addition, the effect of the sensors failure and the extensive levels of noise outliers in the sensor measurements are analyzed. Then, a MM-based diagnosis approach based on the extended Kalman filter (EKF) and the unscented Kalman filter (UKF) is proposed in [19]. But the approaches developed in $[14,19]$ are an AMM approach; the model set is fixed and each filter operates individually and independently of all the other filters; it impossible to establish all possible fault models in advance. In [20], an improved MM approach is developed which can adaptive generate the model set of next level according to the diagnosis result of the previous level. However, the MM approach for gas path fault diagnosis is a fault detection and isolation (FDI) approach that cannot determine the severity of the fault.

Therefore, in this paper, an approach based on interacting multiple model (IMM) and generalized likelihood ratio (GLR) estimation was developed to gas path diagnosis to address the underdetermine estimation problem and improve the performance of the MM-based approach. In this approach, the interacting multiple model (IMM) algorithm is used to consider the interaction between models to detect and isolate gas path fault. And the generalized likelihood ratio (GLR) estimation algorithm is used to estimate the severity of the diagnosed fault. Then a new model set will be adaptively generated according to the FDI and severity estimation results and replaces the old model set to diagnose the multiple faults. Finally, several simulation case studies on a marine gas turbine were conducted, and the performance of the framework for abrupt fault and multiple faults was analyzed.

The remainder of this paper is organized as follows. In Section 2, an introduction of the IMM-based FDI method is presented. The generalized likelihood ratio (GLR) estimation algorithm for gas path fault severity estimation is developed in Section 3. The marine gas turbine model and the case studies are described in Section 4. Section 5 presents the results and discussions of these case studies, and the conclusions of this paper are shown in Section 6.

\section{The IMM-Based FDI Algorithm}

Compared with the AMM-based FDI approach, the filters in IMM-based FDI algorithm interact with each other which lead to improved performance. The IMM-based FDI algorithm is composed of a bank of Kalman filters operating in parallel; each filter is based on a different model that represents the gas turbine healthy and different faulty condition. The diagram of the IMM algorithm is shown in Figure 1; it contains four major steps: (1) interaction and reinitialization, (2) model conditional filtering, (3) model probability update, and (4) estimation fusion [18]. The first step is unique for the IMM compared with the other MM algorithm.

2.1. Hypothetical Model of Gas Turbine. Gas turbine gas path fault will cause the change of the component performance parameters, such mass flow and isentropic efficiency. These performance parameters are used in this paper to represent different gas path fault. Therefore, in the IMM-based FDI 
approach, a set of hypothetical models that represent the different conditions (including health and different fault conditions) of the gas turbine are established. Assume that the gas turbine linearized dynamic model is as shown in

$$
\begin{aligned}
x_{k+1} & =A x_{k}+B u_{k}+w_{k} \\
y_{k} & =C x_{k}+v_{k}
\end{aligned}
$$

where $x$ is the state vector, $y$ is the measurement vector, $u$ is the control input vector, and $w_{k} \sim(0, Q)$ and $\mathrm{v}_{k} \sim(0$, $R$ ) are independent discrete-time process and measurement noises, respectively. To establish the fault hypothetical model, introduce gas path fault indicators and add it to the model [21], as shown in

$$
\begin{aligned}
x_{k+1} & =A x_{k}+B u_{k}+E f_{k}+w_{k} \\
y_{k} & =C x_{k}+D f_{k}+v_{k}
\end{aligned}
$$

where $f$ is the indicators of gas path fault and $f=\sum_{i=1}^{q} b_{i} z_{i}$, where $q$ represents the number of possible gas path faults in the gas turbine, $b_{i}$ represents the fault severity of the $i$ th fault, and it is a scalar. $z_{i}$ represents the location of the fault. When the gas turbine is under the health condition, $f$ is a $6 \times 1$ zero vector, while it is a $6 \times 1$ nonzero vector in the event of fault occur. Extending the $f$ as control variable, the hypothetical model can be established by giving different $f$. Assume that there are $M(M=q+1)$ models in this set of hypothetical models and the $j$ denotes a generic model in it. Then the $j$ th gas turbine linearized dynamic model can be represented by

$$
\begin{gathered}
x_{k+1}^{j}=A x_{k}^{j}+\left[\begin{array}{ll}
B & E
\end{array}\right]\left[\begin{array}{c}
u_{k}^{j} \\
f_{k}^{j}
\end{array}\right]+w_{k} \\
y_{k}^{j}=C x_{k}^{j}+\left[\begin{array}{ll}
0 & D
\end{array}\right]\left[\begin{array}{c}
u_{k}^{j} \\
f_{k}^{j}
\end{array}\right]+v_{k}
\end{gathered}
$$

As shown in (3), by extending the fault indicators to control variables, gas path faults can be detected, isolated, and estimated as actuator faults.

2.2. The IMM Algorithm. As mentioned above, the IMM algorithm contains four steps and the first step is model conditional reinitialization, which is unique for the IMM. It is assumed that the system mode sequence is a first-order Markov chain with transition probabilities $\pi_{i j}=P\left\{m_{k+1}^{j}\right.$ | $\left.m_{k}^{i}\right\}$, where $m_{k}^{i}$ denotes the $i$ th model in effect at $k$. The state estimate and filter covariance of each single-model based filter will be reinitialized from time to time as shown in

$$
\begin{aligned}
& \bar{x}_{k \mid k}^{(i)}=\sum_{j=1}^{M} \widehat{x}_{k \mid k}^{(j)}\left(\frac{\pi_{j i} \mu_{k}^{(j)}}{\sum_{j=1}^{M} \pi_{j i} \mu_{k}^{(j)}}\right) \\
& \bar{P}_{k \mid k}^{(i)}=\sum_{j=1}^{M} P_{k \mid k}^{(j)}\left(\frac{\pi_{j i} \mu_{k}^{(j)}}{\sum_{j=1}^{M} \pi_{j i} \mu_{k}^{(j)}}\right)
\end{aligned}
$$

where $\bar{x}$ and $\bar{P}$ are the values of the reinitialization state estimate and filter covariance, respectively. $\widehat{x}$ and $P$ are the values of the previous state estimate and filter covariance, respectively. $\mu$ is the conditional probability which can be recursively calculated by the Bayesian Law according to the conditional probability value of the previous moment and the Gaussian probability density corresponding to the current filter residual, as shown in

$$
\mu_{k}^{(i)}=\frac{f_{y}\left(y_{k} \mid i, y_{k-1}\right) \mu_{k-1}^{(i)}}{\sum_{j=1}^{M} f_{y}\left(y_{k} \mid j, y_{k-1}\right) \mu_{k-1}^{(j)}}
$$

where $f_{y}\left(y_{k} \mid i, y_{k-1}\right)$ denotes the conditional probability density of the $i$ th filter under the current measurement parameters and $\mu_{k-1}^{(i)}$ denotes the conditional probability of the $i$ th model at the previous moment. The Gaussian probability density function is shown in

$$
\begin{aligned}
& f_{y\left(t_{k}\right) \mid m_{j}, y\left(t_{k-1}\right)}\left(y_{k} \mid m_{j}, y_{k-1}\right) \\
& =\frac{1}{(2 \pi)^{l / 2}\left|S_{j}\right|^{1 / 2}} \exp \left[-\frac{1}{2} \gamma_{j}^{T} S_{j} \gamma_{j}\right]
\end{aligned}
$$

where $l$ is the dimension of the measurement parameters, $S_{j}$ is the innovation covariance, and $\gamma_{j}$ is the innovation of the filter.

2.3. Fault Detection and Isolation Scheme. In the IMM-based FDI approach, the conditional probability of the hypothetical model can be used as an indication of fault due to the fact that it provides a meaningful measure of how likely each fault is at a given time. Therefore, the fault can be detected and isolated through the maximum probability criterion as shown in

$$
\mu_{k}^{(j)}=\arg \max _{i=1 \ldots M} \mu_{k}^{(i)}>\mu_{T}
$$

where the $\mu_{T}$ is a preset detect and isolate threshold. Equation (8) indicates that the conditional probability of the $j$ th hypothetical model is maximum and larger than the threshold, meaning that the $j$ th fault has occurred. Finally, one cycle of the IMM-based FDI algorithm used in this paper is shown in Table 1, and the detail information of the IMM algorithm can refer to [17].

\section{GLR Estimation Algorithm}

One of the important requirements of a gas path fault diagnosis is to determine the fault severity of the occurring fault. However, the IMM-based FDI approach cannot determine the actual fault severity due to it is a probability approach and the direct estimate approach such as Kalman filter based estimation approaches cannot be performed under underdetermine condition. Therefore, a detection-estimation approach (IMM-GLR) was proposed in this paper, the IMMbased FDI algorithm is used to detect and isolate the fault, and then the GLR estimation algorithm is used to estimate the fault severity of the detected fault. 
TABLE 1: The IMM-based FDI algorithm.

\begin{tabular}{l}
\hline Model conditional reinitialization $(i=1,2 \ldots M)$ \\
$\bar{x}_{k \mid k}^{(i)}=\sum_{j=1}^{M} \widehat{x}_{k \mid k}^{(j)}\left(\frac{\pi_{j i} \mu_{k}^{(j)}}{\sum_{j=1}^{M} \pi_{j i} \mu_{k}^{(j)}}\right)$ \\
$\bar{P}_{k \mid k}^{(i)}=\sum_{j=1}^{M} P_{k \mid k}^{(j)}\left(\frac{\pi_{j i} \mu_{k}^{(j)}}{\sum_{j=1}^{M} \pi_{j i} \mu_{k}^{(j)}}\right)$ \\
$\frac{\text { Model conditional filtering }(i=1,2 \ldots M)}{\widehat{x}_{k+1 \mid k}^{(i)}=A \bar{x}_{k \mid k}^{(i)}+[B \quad E]\left[u_{k}^{(i)} f_{k}^{(i)}\right]^{T}}$ \\
$\widehat{P}_{k+1 \mid k}^{(i)}=A \bar{P}_{k \mid k}^{(i)} A^{T}+Q$ \\
$K_{k}^{(i)}=P_{k+1 \mid k}^{(i)} C^{T}\left[C P_{k+1 \mid k}^{(i)} C^{T}+R\right]^{-1}$ \\
$\widehat{x}_{k+1 \mid k+1}^{(i)}=\widehat{x}_{k+1 \mid k}^{(i)}+K_{k}^{(i)}\left[y_{k}-\left(C \widehat{x}_{k+1 \mid k}^{(i)}+[0 \quad D]\left[u_{k}^{(i)} f_{k}^{(i)}\right]^{T}\right)\right]$ \\
$\frac{P_{k+1 \mid k+1}^{(i)}=\widehat{P}_{k+1 \mid k}^{(i)}-K_{k}^{(i)} C \widehat{P}_{k+1 \mid k}^{(i)}}{\text { Model probability update }(i=1,2 \ldots M)}$ \\
$\mu_{k}^{(i)}=\frac{f_{y}\left(y_{k} \mid i, y_{k-1}\right) \mu_{k-1}^{(i)}}{\sum_{j=1}^{M} f_{y}\left(y_{k} \mid j, y_{k-1}\right) \mu_{k-1}^{(j)}}$ \\
$f_{y\left(t_{k}\right) \mid m_{j}, y\left(t_{k-1}\right)}\left(y_{k} \mid m_{j}, y_{k-1}\right)=\frac{1}{(2 \pi)^{l / 2}\left|S_{j}\right|^{1 / 2}} \exp \left[-\frac{1}{2} \gamma_{j}^{T} S_{j} \gamma_{j}\right]$ \\
$\frac{\mu_{k}^{(j)}=\arg \max _{i=1 \ldots M} \mu_{k}^{(i)}}{\text { Estimate fusion }}$ \\
$\widehat{x}_{k+1 \mid k+1}^{M}=\sum_{i=1}^{M} \widehat{x}_{k+1 \mid k+1}^{(i)} \mu_{k}^{(i)}$ \\
$P_{k+1 \mid k+1}^{M} \sum_{i=1}^{(i)} P_{k+1 \mid k+1} \mu_{k}^{(i)}$
\end{tabular}

The GLR method was proposed in [22], then it was improved and modified in $[23,24]$. The GLR method is a detection-estimation method where the time of a fault is an a priori information input to the estimation stage. It makes use of the innovation sequences generated by the filters, and it can estimate the time, location, and severity of the occurring fault with a preset threshold. However, in the IMM-GLR approach, the time and the location of the occurring fault have been determined by the IMM-based FDI algorithm mentioned above. So the detection process of the GLR will be removed and it is mainly used to estimate the fault severity of the detected fault in this paper and no longer needs the preset threshold.

In the GLR, the linearity of the model, Kalman filter, and additive nature of the fault are used to develop recursive relationship between the innovation sequences generated by the filter corresponding to the health model and the model under different fault assumption. In this paper, this recursive relationship will be derived for gas path fault severity estimation.

Each fault, once it occurs, will influence the innovation of the Kalman filter in different ways. In the absence of any fault, the expected value of the innovation is close to zero [23]. However, if the $i$ th fault of severity $b_{i}$ is detected and isolated at time $t$, the expected values of the innovations at any subsequent time can be represented by

$$
E[\gamma(k)]=b_{i} G_{f}(k, t) z_{i}
$$

where the matrix $G_{f}(k, t)$ is referred to as the signature matrices for the $i$ th fault and $t$ denotes the time of the $i$ th fault detected.

In the GLR, the maximum log likelihood ratio of the $i$ th fault can be computed by

$$
\begin{aligned}
& T_{i}=\sup _{i} \sum_{k=t}^{t+N}\left(\kappa_{k}^{i}\right)^{T} S_{k}^{-1} \kappa_{k}^{i} \\
& \kappa_{k}^{i}=\gamma_{k}-\widehat{b}_{i} G_{f}(k, t) z_{i}
\end{aligned}
$$

where $S_{k}$ is the innovation covariance, $\gamma_{k}$ is the innovation of the filter corresponding to the healthy model, and $\widehat{b}_{i}$ denotes the estimation value of the detected fault severity $b_{i}$. Taking derivative and setting to zero, $\widehat{b}_{i}$ can be obtained by

$$
\begin{aligned}
& \widehat{b}_{i}=\frac{d_{i}}{c_{i}} \\
& d_{i}=z_{i}^{T} \sum_{k=t}^{t+N} G_{f}^{T}(k, t) S_{k}^{-1} \gamma_{k} \\
& c_{i}=z_{i}^{T} \sum_{k=t}^{t+N} G_{f}^{T}(k, t) S_{k}^{-1} G_{f}(k, t) z_{i}
\end{aligned}
$$

where the $S_{k}$ and $\gamma_{k}$ are given by Kalman filter directly. As shown in (12)-(14), it needs to obtain the $G_{f}(k, t)$ to determine the value of $\widehat{b}_{i}$. Consider the situation where the $i$ th fault of severity $b_{i}$ detected and isolated at time $t$, the model for all $k \geq t$ as shown in

$$
\begin{aligned}
x_{k+1} & =A x_{k}+B u_{k}+E b_{i} z_{i}+w_{k} \\
y_{k} & =C x_{k}+D b_{i} z_{i}+v_{k}
\end{aligned}
$$

The GLR estimation algorithm is based on the innovation sequences generated by the filter corresponding to the health model, and the model for gas turbine health condition is

$$
\begin{aligned}
x_{k+1} & =A x_{k}+B u_{k}+w_{k} \\
y_{k} & =C x_{k}+v_{k}
\end{aligned}
$$

So the expected values of the innovation of filter is

$$
\begin{aligned}
E\left[\gamma_{k}\right] & =E\left[y_{k}-\widehat{y}_{k}\right] \\
& =E\left[C x_{k}+D b_{i} z_{i}+v_{k}-C \widehat{x}_{k \mid k-1}\right] \\
& =E\left[C\left(x_{k}-\widehat{x}_{k \mid k-1}\right)+D b_{i} z_{i}+v_{k}\right] \\
& =E\left[C\left[-A \delta \widehat{x}_{k-1}+E b_{i} z_{i}+w_{k-1}\right]+D b_{i} z_{i}+v_{k}\right]
\end{aligned}
$$

Substitute (17) into (9), then (18) can be obtained:

$$
G_{f}(k, t)=-C A J_{f}(k-1, t)+C E+D
$$


TABle 2: Description of the gas path fault.

\begin{tabular}{lcc}
\hline No. & Fault & description \\
\hline 1 & Health & $\mathrm{H}$ \\
\hline 2 & Change in compressor mass flow $m_{c}$ & $\mathrm{~F}_{\mathrm{mc}}$ \\
\hline 3 & Change in compressor efficiency $\eta_{c}$ & $\mathrm{~F}_{\eta c}$ \\
\hline 4 & Change in compressor turbine mass flow $m_{c t}$ & $\mathrm{~F}_{\mathrm{mct}}$ \\
\hline 5 & Change in compressor turbine efficiency $\eta_{c t}$ & $\mathrm{~F}_{\eta c t}$ \\
\hline 6 & Change in power turbine mass flow $m_{p t}$ & $\mathrm{~F}_{\mathrm{mpt}}$ \\
\hline 7 & Change in power turbine efficiency $\eta_{p t}$ & $\mathrm{~F}_{\eta \mathrm{pt}}$ \\
\hline
\end{tabular}

where the $J_{f}(k-1, t)$ denotes the signature matrix for state correction and is defined as

$$
E\left[\delta \widehat{x}_{k}\right]=b_{i} J_{f}(k, t) z_{i}
$$

where the $\delta \widehat{x}_{k}$ is the difference between the true value and estimation value of the state variables, and it can obtained by

$$
\begin{aligned}
\delta \widehat{x}_{k}= & \widehat{x}_{k \mid k}-x_{k}=\widehat{x}_{k \mid k-1}+K_{k}\left[y_{k}-C \widehat{x}_{k \mid k-1}\right]-x_{k} \\
= & {\left[I-K_{k} C\right] \widehat{x}_{k \mid k-1}+K_{k} y_{k}-x_{k} } \\
= & {\left[I-K_{k} C\right] \widehat{x}_{k \mid k-1}+K_{k}\left[C x_{k}+D b_{i} z_{i}+v_{k}\right]-x_{k} } \\
= & {\left[I-K_{k} C\right]\left[\widehat{x}_{k \mid k-1}-x_{k}\right]+x_{k}+K_{k}\left[D b_{i} z_{i}+v_{k}\right] } \\
& -x_{k} \\
= & {\left[I-K_{k} C\right]\left[A \delta \hat{x}_{k-1}-E b_{i} z_{i}-w_{k-1}\right] } \\
& +K_{k}\left[D b_{i} z_{i}+v_{k}\right]
\end{aligned}
$$

where $K_{k}$ is the Kalman gain of the filter corresponding to the healthy model. Substitute (20) into (19), then (21) can be obtained.

$$
J_{f}(k, t)=A J_{f}(k-1, t)-K_{k} G_{f}(k, t)-E
$$

Therefore, the signature matrices for gas path severity estimation can be computed using the recursive relations as shown in (18) and (21), and then the severity of the detected fault can be estimated using (12)-(14).

\section{Description of Case Study}

In this paper, the proposed IMM-GLR gas path faults detection, isolation, and estimation approach was applied to a marine gas turbine engine as shown in Figure 2. The gas turbine engine mainly contains compressor, combustion chamber, compressor turbine, and the power turbine. The $P_{i}$ and $T_{i}$ in Figure 2 denote the inlet and outlet temperature and pressure of these components, and $w_{f}$ denotes the fuel mas flow.

Gas path faults will change the structure of components, thereby changing the characteristics map, and then the gas turbine performance will degrade, resulting in changes in gas turbine performance parameters, such as the corrected mass flow and the isentropic efficiency. In this paper, mainly consider the following six performance parameters as shown

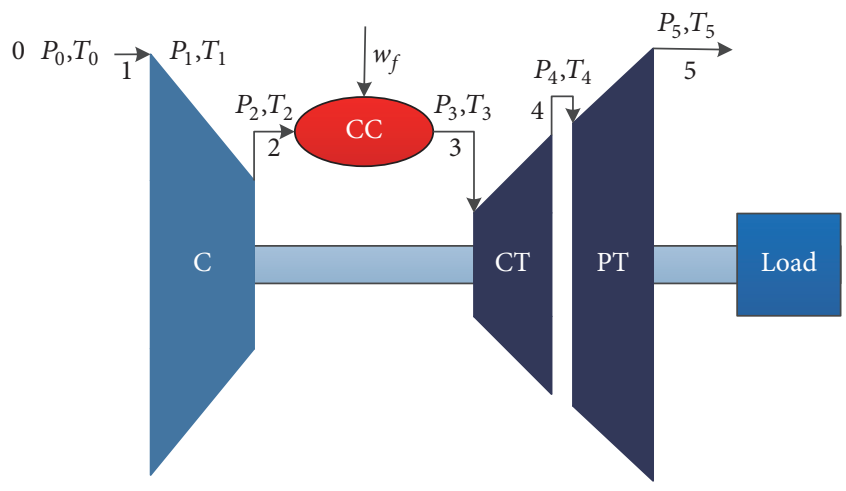

FIGURE 2: Schematic of the marine gas turbine.

in Table 2, and the fault indicators $\mathrm{F}_{\mathrm{mc}}, \mathrm{F}_{\eta \mathrm{c}}, \mathrm{F}_{\mathrm{mct}}, \mathrm{F}_{\eta \mathrm{ct}}, \mathrm{F}_{\mathrm{mpt}}$, and $\mathrm{F}_{\eta \mathrm{pt}}$ are used to describe these faults. When a fault has not occurred, the indicator is equal to one; otherwise the indicator is not equal to one.

In this paper, the performance of the propose IMM-GLR approach was demonstrated using the design point linearized model of the marine gas turbine engine. The model can be describe by

$$
\begin{aligned}
x_{k+1} & =A x_{k}+B u_{k}+w_{k} \\
y_{k} & =C x_{k}+D u_{k}+v_{k}
\end{aligned}
$$

In this model, the state vector $x=\left[N_{1}, N_{2}, T_{3}, P_{3}, P_{4}\right]$ consists of gas generator speed $N_{1}(\mathrm{rpm} / \mathrm{min})$, power turbine speed $N_{2}(\mathrm{rpm} / \mathrm{min})$, inlet temperature $T_{3}(\mathrm{~K})$ and pressure $P_{3}(\mathrm{~Pa})$ of compressor turbine, and the inlet pressure $P_{4}(\mathrm{~Pa})$ of power turbine. The measurement vector $y=$ $\left[N_{1}, N_{2}, P_{2}, T_{4}\right]$, the $P_{2}(\mathrm{~Pa})$ denotes the outlet pressure of the compressor, and the $T_{4}(\mathrm{~K})$ denotes the outlet temperature of the compressor turbine. In this paper, the hypothetical models are established by extending the fault indicators to control variables, so the control vector $u=$ $\left[w_{f}, \mathrm{~F}_{\mathrm{mc}}, \mathrm{F}_{\eta \mathrm{c}}, \mathrm{F}_{\mathrm{mct}}, \mathrm{F}_{\eta \mathrm{ct}}, \mathrm{F}_{\mathrm{mpt}}, \mathrm{F}_{\eta \mathrm{pt}}\right]$. Given different indicator, different fault model can be established. In addition, all parameters in this linear model use the percentage change, the sampling period $T=0.02 \mathrm{~s}$, and the independent discretetime process and measurement noises covariance are $\mathrm{Q}=$ $(0.01)^{2} \mathrm{I}$ and $\mathrm{R}=(0.1)^{2} \mathrm{I}$, respectively. Moreover, the matrices $A, B, C, D$ are as follows: 


$$
\begin{aligned}
A & =\left[\begin{array}{cccccc}
0.9842 & -0.0112 & 0.0041 & 0.0175 & -0.0119 \\
-0.0118 & 0.7575 & 0.0470 & 0.0354 & 0.0831 \\
0.0226 & -0.0022 & 0.9105 & -0.0165 & -0.0092 \\
0.0799 & 0.0086 & -0.1329 & 0.8907 & -0.0121 \\
-0.0218 & -0.1302 & 0.0091 & 0.2644 & 0.7407
\end{array}\right] \\
B & =\left[\begin{array}{cccccccc}
0.0058 & -0.0193 & 0.0164 & 0.0060 & 0.0162 & -0.0024 & 0.0036 \\
0.0089 & 0.0003 & -0.0049 & 0.0555 & -0.0271 & 0.0398 & 0.0745 \\
0.0506 & -0.0009 & -0.0238 & -0.0282 & -0.0043 & -0.0103 & 0.0010 \\
0.0883 & 0.0671 & -0.0482 & -0.1156 & 0.0022 & -0.0208 & -0.0019 \\
0.0342 & 0.0348 & -0.0199 & 0.3027 & -0.0602 & -0.2701 & 0.0507
\end{array}\right] \\
C & =\left[\begin{array}{cccccc}
1 & 0 & 0 & 0 & 0 &
\end{array}\right]
\end{aligned}
$$

$$
D=\left[\begin{array}{ccccccc}
0 & 0 & 0 & 0 & 0 & 0 & 0 \\
0 & 0 & 0 & 0 & 0 & 0 & 0 \\
0 & 0 & 0 & 0 & 0 & 0 & 0 \\
-0.0310 & 0.0092 & 0.0219 & 0.0097 & -0.3015 & 0.0769 & -0.0429
\end{array}\right]
$$

Based on the linear model mentioned above, several case studies of the proposed IMM-GLR based gas path fault diagnosis approach were conducted. In the IMM-based FDI algorithm, an initial model set which contains a health model and 6 different fault models needs to be established, so a fault detectable analysis was studied to determine the reasonable initial fault severity for the 6 fault models. Then based on the Monte-Carlo simulation, the performance of the IMM-GLR approach for single gas path fault diagnosis was analyzed. Finally, in the scenarios of multiple faults, a comparative analysis of the performance of IMM-GLR approach and IMM approach was conducted.

\section{Simulation Results and Discussion}

To evaluate the detection, isolation, and estimation performance of the IMM-GLR approach, the following performance measures are used in this paper: corrected detection and identification (CDI), incorrect fault identification (IFI), and missed detection (MD) [18]. The CDI denotes the model that is closest to the actual condition of the gas turbine which has a probability that is largest and exceeds the preset threshold $\mu_{T}$. The IFI denotes the model with a probability over $\mu_{T}$ which is not the one closest to the actual fault condition of the gas turbine. The MD denotes the health model with the largest probability and over $\mu_{T}$ while the actual condition is faulty condition. Therefore, the larger the CDI, the better the performance of the IMM-GLR approach.
In addition, the root-mean-square error (RMSE) of the fault indicators is used to evaluate the estimation accuracy and is defined as

$$
\operatorname{RMSE}(\widehat{F})=\sqrt{\frac{1}{N} \sum_{i=1}^{N}(F-\widehat{F})^{2}}
$$

where $N$ denotes the number of Monte-Carlo simulation, $\mathrm{F}$ denotes the actual severity of the simulated fault, and the $\widehat{F}$ denotes the estimation severity of the fault.

To avoid the conditional probability of the model close to zero and change slowly when the fault occurs, a minimum conditional probability 0.001 is set for each model in this paper. And the preset detection and isolation threshold $\mu_{T}$ is set to 0.98 .

5.1. Minimum Detectable Severity Analysis. The design of the model set has an important influence on the performance of the IMM-based FDI approach, it is necessary to determine the reasonable initial fault severity of each fault model. Therefore, the minimum detectable fault severity of each gas path fault is analyzed under four different initial fault severities $(-0.5 \%,-1 \%,-1.5 \%$, and $-2 \%)$, as shown in Table 3. It can be seen from the table that the minimum detectable severity of each fault increases with the increase of the initial fault severity, so it needs to choose a small initial severity to detect the partial fault. However, when the initial severity is $-0.5 \%$, the corresponding detectable severity has slight effect 
TABLE 3: The minimum detectable severity of each fault under different initial fault severity.

\begin{tabular}{lllll}
\hline Fault type & \multicolumn{3}{c}{ Initial severity of the model set (\%) } \\
& -0.5 & -1.0 & -1.5 & -2 \\
\hline $\mathrm{F}_{\mathrm{mc}}$ & -0.3 & -0.5 & -0.8 & -1.0 \\
\hline $\mathrm{F}_{\eta \mathrm{c}}$ & -0.4 & -0.7 & -1.1 & -1.4 \\
\hline $\mathrm{F}_{\mathrm{mct}}$ & -0.3 & -0.5 & -0.8 & -1.0 \\
\hline $\mathrm{F}_{\eta \mathrm{ct}}$ & -0.4 & -0.5 & -1.1 & -1.5 \\
\hline $\mathrm{F}_{\mathrm{mpt}}$ & -0.5 & -0.7 & -0.9 & -1.0 \\
\hline $\mathrm{F}_{\eta \mathrm{pt}}$ & -0.3 & -0.5 & -0.8 & -1.0 \\
\hline
\end{tabular}

TABLE 4: The initial model set of the IMM-based FDI algorithm.

\begin{tabular}{|c|c|}
\hline Model set & $\begin{array}{c}\text { Corresponding control vector } f^{(i)} \\
\qquad i=1,2, \ldots 7\end{array}$ \\
\hline 1\# (health) & {$\left[\begin{array}{llllll}0 & 0 & 0 & 0 & 0 & 0\end{array}\right]^{\mathrm{T}}$} \\
\hline $2 \#\left(\mathrm{~F}_{\mathrm{mc}}=0.99\right)$ & {$\left[\begin{array}{llllll}-1 & 0 & 0 & 0 & 0 & 0\end{array}\right]^{\mathrm{T}}$} \\
\hline 3\# $\left(\mathrm{F}_{\eta \mathrm{c}}=0.99\right)$ & {$\left[\begin{array}{llllll}0 & -1 & 0 & 0 & 0 & 0\end{array}\right]^{\mathrm{T}}$} \\
\hline $4 \#\left(\mathrm{~F}_{\mathrm{mct}}=0.99\right)$ & {$\left[\begin{array}{llllll}0 & 0 & -1 & 0 & 0 & 0\end{array}\right]^{\mathrm{T}}$} \\
\hline $5 \#\left(\mathrm{~F}_{\eta \mathrm{ct}}=0.99\right)$ & {$\left[\begin{array}{lllllll}0 & 0 & 0 & -1 & 0 & 0\end{array}\right]^{\mathrm{T}}$} \\
\hline 6\# $\left(\mathrm{F}_{\mathrm{mpt}}=0.99\right)$ & {$\left[\begin{array}{lllllll}0 & 0 & 0 & 0 & -1 & 1\end{array}\right]^{\mathrm{T}}$} \\
\hline $7 \#\left(\mathrm{~F}_{\eta \mathrm{pt}}=0.99\right)$ & {$\left[\begin{array}{lllllll}0 & 0 & 0 & 0 & 0 & -1\end{array}\right]^{\mathrm{T}}$} \\
\hline
\end{tabular}

on the performance of the gas turbine, which may be similar to the influence of the noise. Therefore, the chosen initial severity of the fault in this paper is $-1 \%$, and the initial model set of the IMM-based FDI algorithm is shown in Table 4.

In the Table 4, the initial model set contains 7 hypothetical models, one of which is the health model and the other 6 different fault models represent the 6 gas path faults. For each fault model, the corresponding initial fault severity is $-1 \%$, so for the $f^{(i)}$ of each model, the element corresponding to the fault location has a value of -1 , while the other elements are zero. At the initial time, assuming that the gas turbine is in a health condition, so the conditional probability of the health model is one, while the conditional probability of the other hypothetical model is zero.

5.2. Single Fault Diagnosis Analysis. The proposed IMMGLR approach is a detection-estimation approach, where the IMM-based FDI algorithm is used to detect and isolate fault and the GLR is used to estimate the severity of the detected fault. Figures 3 and 4 show the diagnosis result based on the IMM-GLR approach in the scenarios of compressor mass flow $\left(\mathrm{F}_{\mathrm{mc}}\right)$ decreases $1.3 \%$ at $\mathrm{t}=5 \mathrm{~s}$. Figure 3 shows the detection result which is the conditional probability of each hypothetical model and Figure 4 shows the estimation result which is the fault severity estimation of the detected fault.

As shown in Figure 3, when the $\mathrm{F}_{\mathrm{mc}}$ decreases $1.3 \%$ fault occurs, the conditional probability of health model decreases to zero, while the probability of the model closest to the actual fault (namely, the 2\# model) increases and exceeds the preset threshold $(0.98)$, so that the $\mathrm{F}_{\mathrm{mc}}$ fault is detected and isolated. However, the IMM-based FDI algorithm cannot determine the fault severity and only determine the location and occurrence time of fault. So the GLR is used to estimate

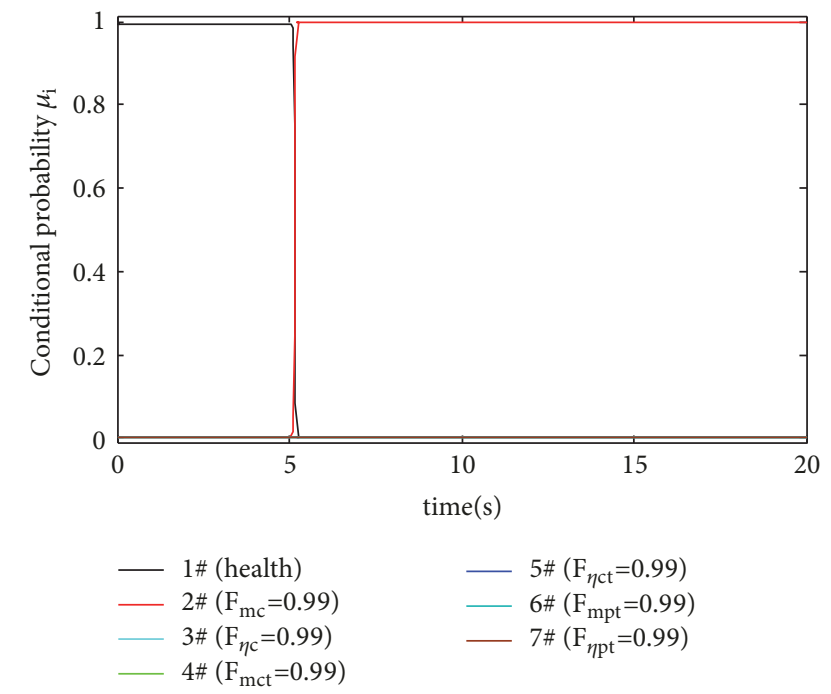

FIgure 3: The conditional probability of the model set in the scenarios of compressor mass flow decreases $1.3 \%$ at $\mathrm{t}=5 \mathrm{~s}$.

the severity and the estimation result is shown in Figure 4. As shown in Figure 4, the severity of the detected fault is accurately estimated by the GLR approach.

To evaluate the performance of the IMM-GLR approach for single fault, Monte-Carlo simulation analysis is performed. In this paper, perform 100 simulations for each fault and the severity of the each simulation is in the interval [$3 \%,-0.5 \%]$ and then analyzes the CDI, IFI, and MD for each fault. The simulation results are shown in Table 5, where the left side is the confusion matrix of the FDI result and the right 
TABLE 5: Single fault diagnosis result based on the IMM-GLR approach after 100 Monte Carlo runs.

\begin{tabular}{|c|c|c|c|c|c|c|c|c|c|c|c|}
\hline \multirow{2}{*}{ Fault Type } & \multicolumn{7}{|c|}{ FDI Result } & \multirow{2}{*}{ CDI } & \multirow{2}{*}{ IFI } & \multirow{2}{*}{$\mathrm{MD}$} & \multirow{2}{*}{ RMSE } \\
\hline & $\mathrm{F}_{\mathrm{mc}}$ & $\mathrm{F}_{\eta \mathrm{c}}$ & $\mathrm{F}_{\mathrm{mct}}$ & $\mathrm{F}_{\eta \mathrm{t}}$ & $\mathrm{F}_{\mathrm{mpt}}$ & $\mathrm{F}_{\eta \mathrm{pt}}$ & No Fault & & & & \\
\hline $\mathrm{F}_{\mathrm{mc}}$ & 100 & 0 & 0 & 0 & 0 & 0 & 0 & 1 & 0 & 0 & 0.0062 \\
\hline $\mathrm{F}_{\eta \mathrm{c}}$ & 0 & 100 & 0 & 0 & 0 & 0 & 0 & 1 & 0 & 0 & 0.0085 \\
\hline $\mathrm{F}_{\mathrm{mct}}$ & 0 & 0 & 98 & 0 & 0 & 2 & 0 & 0.98 & 0.02 & 0 & 0.0072 \\
\hline $\mathrm{F}_{\eta \mathrm{ct}}$ & 0 & 0 & 0 & 100 & 0 & 0 & 0 & 1 & 0 & 0 & 0.0075 \\
\hline $\mathrm{F}_{\mathrm{mpt}}$ & 0 & 0 & 0 & 0 & 93 & 0 & 7 & 0.93 & 0 & 0.07 & 0.0154 \\
\hline $\mathrm{F}_{\eta \mathrm{pt}}$ & 0 & 0 & 0 & 0 & 0 & 100 & 0 & 1 & 0 & 0 & 0.0562 \\
\hline
\end{tabular}

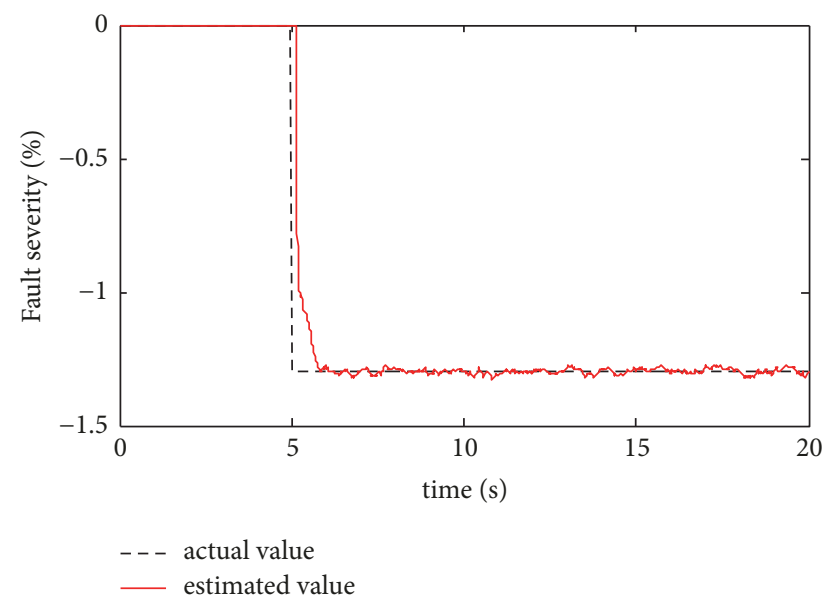

FIGURE 4: Fault severity estimation results based on the GLR for the detected fault in the scenarios of compressor mass flow decreases $1.3 \%$ at $\mathrm{t}=5 \mathrm{~s}$.

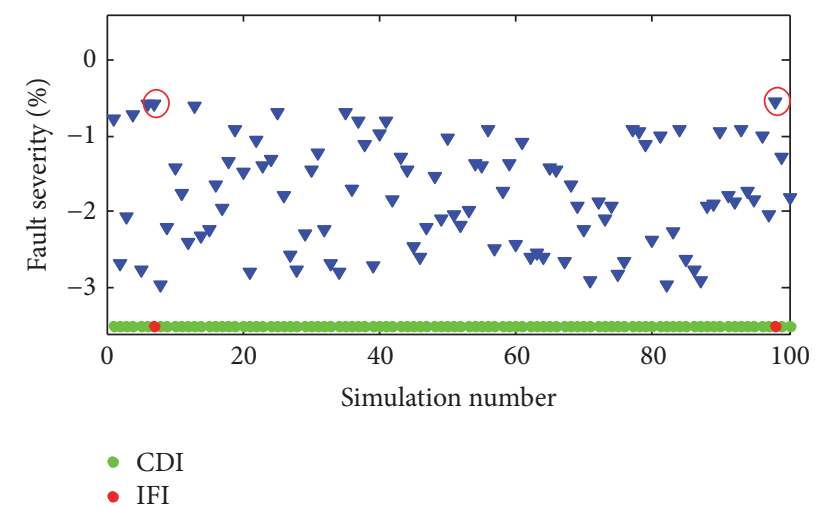

FIGURE 5: The severity of the simulated $\mathrm{F}_{\eta c}$ and the diagnosis result.

side is the value of the performance measures and the RMSE of the estimated severity.

As shown in Table 5, the IMM-GLR approach accurately detects and isolates the $\mathrm{F}_{\mathrm{mc}}, \mathrm{F}_{\eta \mathrm{c}}, \mathrm{F}_{\eta \mathrm{t}}$, and $\mathrm{F}_{\eta \mathrm{pt}}$ faults during 100 Monte-Carlo simulations. However, 2 IFI occurs for $\mathrm{F}_{\text {mct }}$ fault and $7 \mathrm{MD}$ occurs for $\mathrm{F}_{\mathrm{mpt}}$. The severity of the 100 simulations and the corresponding diagnosis results of the $\mathrm{F}_{\mathrm{mct}}$ fault and $\mathrm{F}_{\mathrm{mpt}}$ fault are shown in Figures 5 and 6, respectively. It can be seen from these figures that the main cause of IFI of the $\mathrm{F}_{\mathrm{mct}}$ fault and $\mathrm{MD}$ of $\mathrm{F}_{\mathrm{mpt}}$ fault is that the severity of the simulated

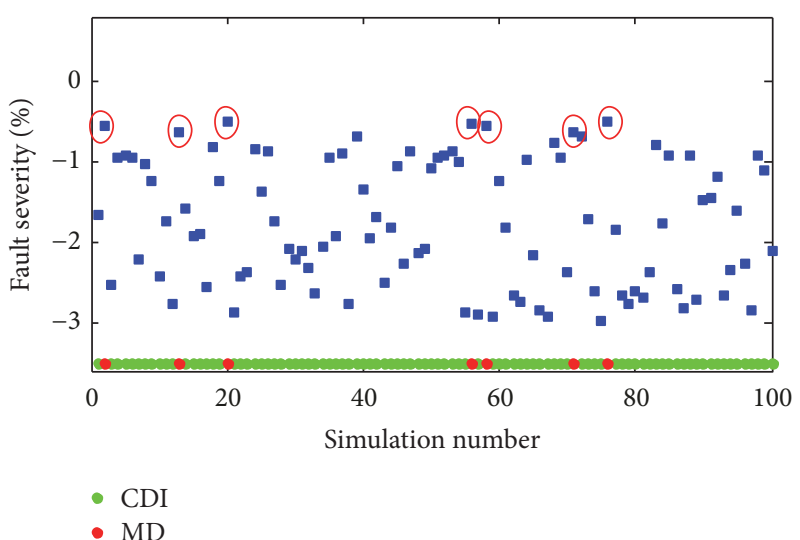

FIGURE 6: The severity of the simulated $\mathrm{F}_{\mathrm{mpt}}$ and the diagnosis result.

fault is less than corresponding minimum detectable severity. Therefore, when the severity of the fault is larger than the corresponding minimum detectable severity, both faults can be accurately detected and isolated.

In addition, when the fault is detected and isolated, the GLR is used to estimate the severity of the detected fault and the RMSE is used to evaluate the estimation accuracy. The RMSE of estimated severity corresponding to each fault is shown in Table 5; it can be seen that the GLR approach can accurately estimate the severity of all detected faults.

5.3. Multiple Fault Diagnosis Analysis. In practice, multiple faults exist in which a second fault occurs during first fault. In this scenarios, no model in the model set matches or is close to the actual fault condition. Therefore, to maintain the performance of the IMM-based FDI algorithm, it is necessary to update the model set to diagnose multiple faults after diagnosing the first fault. In this paper, the new model set will be adaptively generated based on the IMMGLR approach. Here, only two different faults are considered because the proposed approach can be applied to more faults straightforwardly.

The IMM-based FDI approach can determine the location of the occurring fault and the GLR can estimate the severity of the detected fault. Therefore, a new model set will be adaptively generated based on the location and severity of the first fault. The initial model set contains a health model (1\#) and 6 different fault models (2\#-7\#), and the initial severity of each fault is $-1 \%$. When the first fault is diagnosed, 


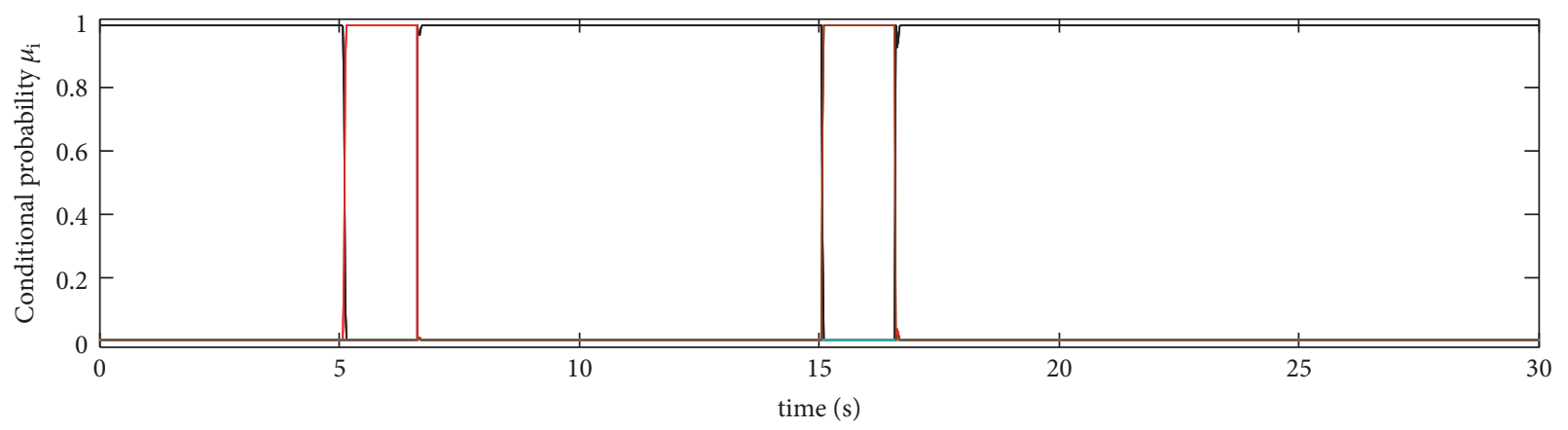

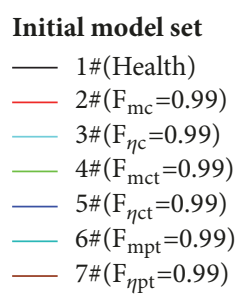

Updated model set 1

1 1\# $\left(\mathrm{F}_{\mathrm{mc}}=0.98405\right)$

2\# $\left(\mathrm{F}_{\mathrm{mc}}=0.97405\right)$

3\# $\left(\mathrm{F}_{\mathrm{mc}}=0.98405, \mathrm{~F}_{\eta \mathrm{c}}=0.99\right)$

- $4 \#\left(\mathrm{~F}_{\mathrm{mc}}=0.98405, \mathrm{~F}_{\mathrm{mct}}=0.99\right)$

- $5 \#\left(\mathrm{~F}_{\mathrm{mc}}=0.98405, \mathrm{~F}_{\eta \mathrm{ct}}=0.99\right)$

- $6 \#\left(\mathrm{~F}_{\mathrm{mc}}=0.98405, \mathrm{~F}_{\mathrm{mpt}}=0.99\right)$

- 7\# $\left(\mathrm{F}_{\mathrm{mc}}=0.98405, \mathrm{~F}_{\eta \mathrm{pt}}=0.99\right)$
Updated model set 2

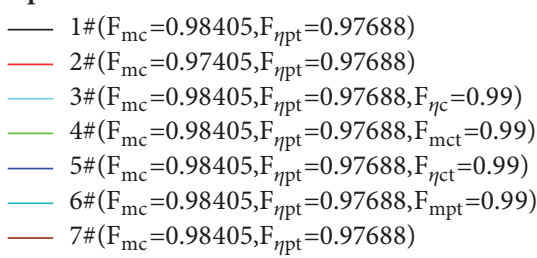

(a) Diagnosis result of multiple fault based on IMM-GLR approach

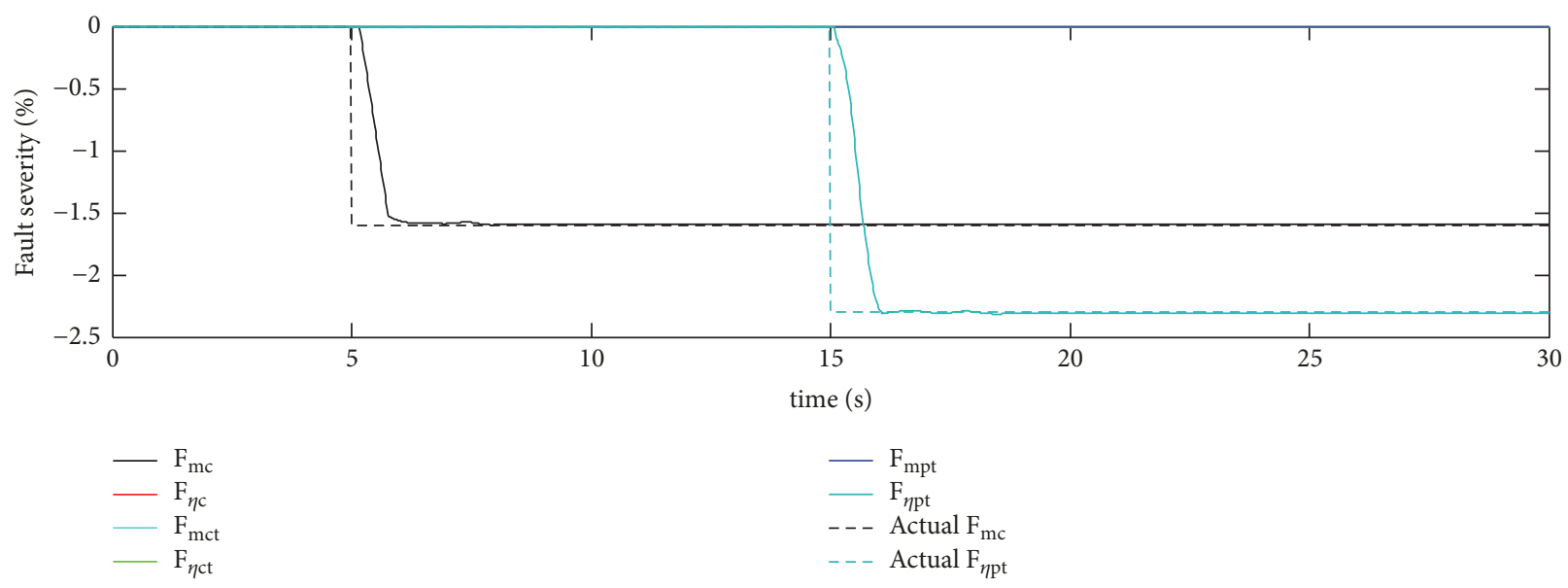

(b) Severity estimation of the detected faults based on GLR estimation approach

Figure 7: Multiple faults diagnosis and estimation results based on the IMM-GLR approach in the scenarios of the $\mathrm{F}_{\mathrm{mc}}$ decreases $1.6 \%$ at time $\mathrm{t}=5 \mathrm{~s}$ and the $\mathrm{F}_{\eta \mathrm{pt}}$ decreases $2.3 \%$ at time $\mathrm{t}=15 \mathrm{~s}$.

the 7 models in the new model set should contain the first fault on the basis of the old model set, and the corresponding fault severity is the estimated severity $\widehat{F}$. Particularly, the severity of the model corresponding to the first fault in the old model set will increase in the new model set to represent more serious faults. Then the conditional probability, state estimate, and filter covariance of the models in the new model set will be reinitialized and continue to diagnose the next fault.

To better illustrate the multiple faults diagnosis process, a case study is conducted. Figure 7 shows the multiple faults diagnosis and estimation results based on the IMM-GLR approach in the scenarios of the $\mathrm{F}_{\mathrm{mc}}$ decreases $1.6 \%$ at time $\mathrm{t}=5 \mathrm{~s}$ and the $\mathrm{F}_{\eta \mathrm{pt}}$ decreases $2.3 \%$ at time $\mathrm{t}=15 \mathrm{~s}$. As shown in Figure 7, when the $\mathrm{F}_{\mathrm{mc}}$ decreases $1.6 \%$ fault occurs at time $\mathrm{t}=5 \mathrm{~s}$, the model (2\# in initial model set) that is closest to the fault is accurately detected and isolated by the IMM-based FDI algorithm as shown in Figure 7(a), then the estimated severity of the $\mathrm{F}_{\mathrm{mc}}$ fault based on the GLR is $-1.595 \%$ as shown in Figure 7(b). After the first fault being diagnosed, the model set will update (updated model set 1) and the conditional probability will be reinitialized. When the $\mathrm{F}_{\eta \mathrm{pt}}$ decreases $2.3 \%$ fault occurs at time $t=15 \mathrm{~s}$, the model ( $7 \#$ in updated model set 1) that is closest to the fault is accurately detected and isolated and the estimated severity of the $\mathrm{F}_{\eta \mathrm{pt}}$ fault is $-2.312 \%$. Then the model set will be updated again (updated model set 2) and the conditional probability will be reinitialized again.

It also can be seen from the diagnosis process shown in Figure 7 that, in the proposed IMM-GLR approach, the new model set is generated based on the estimated severity of the diagnosed fault, which is different to the traditional IMM approach. Figure 8 shows the comparison of the model set change between the traditional IMM approach and the proposed IMM-GLR approach in diagnosing the above two faults. As shown in Figure 8, for the traditional IMM 


\begin{tabular}{|c|c|c|c|c|c|c|c|c|c|}
\hline \multicolumn{2}{|c|}{ Initial model set } & \multicolumn{3}{|c|}{$\mathrm{F}_{\mathrm{mc} \text { FDI }}$} & \multicolumn{3}{|c|}{$\mathrm{F}_{\eta \mathrm{pt} \text { FDI }}$} & & \\
\hline Model & $f^{(i)} i=1,2, \ldots 7$ & Model & $f^{(i)} i=1,2, \ldots 7$ & Model & $f^{(i)} i=1,2, \ldots 7$ & Model & $f^{(i)} i=1,2, \ldots 7$ & Model & $f^{(i)} i=1,2, \ldots 7$ \\
\hline $1 \#$ & {$\left[\begin{array}{llllll}0 & 0 & 0 & 0 & 0 & 0\end{array}\right]^{\mathrm{T}}$} & $1 \#$ & $\left.\begin{array}{llllll}-1 & 0 & 0 & 0 & 0 & 0\end{array}\right]^{\mathrm{T}}$ & $1 \#$ & $\left.\begin{array}{lllllll}-2 & 0 & 0 & 0 & 0 & 0\end{array}\right]^{\mathrm{T}}$ & $1 \#$ & {$\left[\begin{array}{lllllll}-2 & 0 & 0 & 0 & 0 & -1\end{array}\right]^{\mathrm{T}}$} & $1 \#$ & {$\left[\begin{array}{llllll}-2 & 0 & 0 & 0 & 0 & -2\end{array}\right]^{\mathrm{T}}$} \\
\hline 2\# & {$\left[\begin{array}{llllll}-1 & 0 & 0 & 0 & 0 & 0\end{array}\right]^{\mathrm{T}}$} & 2\# & {$\left[\begin{array}{llllll}-2 & 0 & 0 & 0 & 0 & 0\end{array}\right]^{\mathrm{T}}$} & 2\# & {$\left[\begin{array}{llllll}-3 & 0 & 0 & 0 & 0 & 0\end{array}\right]^{\mathrm{T}}$} & 2\# & {$\left[\begin{array}{lllllll}-3 & 0 & 0 & 0 & 0 & -1\end{array}\right]^{\mathrm{T}}$} & $2 \#$ & {$\left[\begin{array}{llllll}-3 & 0 & 0 & 0 & 0 & -2\end{array}\right]^{\mathrm{T}}$} \\
\hline 3\# & {$\left[\begin{array}{llllll}0 & -1 & 0 & 0 & 0 & 0\end{array}\right]^{\mathrm{T}}$} & $3 \#$ & {$\left[\begin{array}{lllll}-1 & -1 & 0 & 0 & 0\end{array}\right]^{\mathrm{T}}$} & 3\# & $\left.\begin{array}{|llllll}-2 & -1 & 0 & 0 & 0 & 0\end{array}\right]^{\mathrm{T}}$ & $3 \#$ & $\left.\begin{array}{|llllll}-2 & -1 & 0 & 0 & 0 & -1\end{array}\right]^{\mathrm{T}}$ & $3 \#$ & 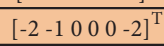 \\
\hline $4 \#$ & {$\left[\begin{array}{llllll}0 & 0 & -1 & 0 & 0 & 0\end{array}\right]^{\mathrm{T}}$} & $4 \#$ & $\left.\begin{array}{llllll}-1 & 0 & -1 & 0 & 0 & 0\end{array}\right]^{\mathrm{T}}$ & $4 \#$ & {$\left[\begin{array}{llllll}-2 & 0 & -1 & 0 & 0 & 0\end{array}\right]^{\mathrm{T}}$} & $4 \#$ & $\left.\begin{array}{llllll}-2 & 0 & -1 & 0 & 0 & -1\end{array}\right]^{\mathrm{T}}$ & $4 \#$ & {$\left[\begin{array}{llllll}-2 & 0 & -1 & 0 & 0 & -2\end{array}\right]^{\mathrm{T}}$} \\
\hline $5 \#$ & $\left.\begin{array}{llllll}0 & 0 & 0 & -1 & 0 & 0\end{array}\right]^{\mathrm{T}}$ & 5\# & $\left.\begin{array}{lllll}-1 & 0 & 0 & -1 & 0\end{array}\right]^{\mathrm{T}}$ & $5 \#$ & $\left.\begin{array}{|llllll}-2 & 0 & 0 & -1 & 0 & 0\end{array}\right]^{\mathrm{T}}$ & $5 \#$ & {$\left[\begin{array}{llllll}-2 & 0 & 0 & -1 & 0 & -1\end{array}\right]^{\mathrm{T}}$} & 5\# & {$\left[\begin{array}{llllll}-2 & 0 & 0 & -1 & 0 & -2\end{array}\right]^{\mathrm{T}}$} \\
\hline 6\# & {$\left[\begin{array}{llllll}0 & 0 & 0 & 0 & -1 & 0\end{array}\right]^{\mathrm{T}}$} & $6 \#$ & $\left.\begin{array}{|lllll}-1 & 0 & 0 & 0 & -1\end{array}\right]^{\mathrm{T}}$ & $6 \#$ & {$\left[\begin{array}{lllllll}-2 & 0 & 0 & 0 & -1 & 0\end{array}\right]^{\mathrm{T}}$} & 6\# & {$\left[\begin{array}{llllll}-2 & 0 & 0 & 0 & -1 & -1\end{array}\right]^{\mathrm{T}}$} & $6 \#$ & {$\left[\begin{array}{llllll}-2 & 0 & 0 & 0 & -1 & -2\end{array}\right]^{\mathrm{T}}$} \\
\hline $7 \#$ & $\left.\begin{array}{llllll}0 & 0 & 0 & 0 & 0 & -1\end{array}\right]^{\mathrm{T}}$ & $7 \#$ & 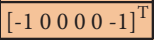 & 7\# & {$\left[\begin{array}{llllll}-2 & 0 & 0 & 0 & 0 & -1\end{array}\right]^{\mathrm{T}}$} & $7 \#$ & {$\left[\begin{array}{llllll}-2 & 0 & 0 & 0 & 0 & -2\end{array}\right]^{\mathrm{T}}$} & 7\# & {$\left[\begin{array}{llllll}-2 & 0 & 0 & 0 & 0 & -3\end{array}\right]^{\mathrm{T}}$} \\
\hline
\end{tabular}

(a) Process of IMM-based FDI in the scenarios of the $\mathrm{F}_{\mathrm{mc}}$ and the $\mathrm{F}_{\eta \mathrm{pt}}$ fault

\begin{tabular}{|c|c|c|c|c|c|c|c|}
\hline \multicolumn{2}{|c|}{ Initial model set } & \multicolumn{2}{|l|}{$\mathrm{F}_{\mathrm{mc}}$ FDI } & \multicolumn{3}{|c|}{$\mathrm{F}_{\eta \mathrm{pt}} \mathrm{FDI}$} & \multirow[b]{2}{*}{$f^{(i)} i=1,2, \ldots 7$} \\
\hline Model & $f^{(i)} i=1,2, \ldots 7$ & \multirow{3}{*}{$\begin{array}{l}\text { Severity estimation } \\
\text { of } F_{m c}\end{array}$} & Model & $f^{(i)} i=1,2, \ldots 7$ & \multirow{3}{*}{$\begin{array}{c}\text { Severity estimation } \\
\text { of } \mathrm{F}_{\eta \mathrm{pt}}\end{array}$} & Model & \\
\hline $1 \#$ & $\left.\begin{array}{llllll} & 0 & 0 & 0 & 0 & 0\end{array}\right]^{\mathrm{T}}$ & & $1 \#$ & {$\left[\begin{array}{llllll}-1.595 & 0 & 0 & 0 & 0 & 0\end{array}\right]^{\mathrm{T}}$} & & $1 \#$ & {$\left[\begin{array}{llllllll}-1.595 & 0 & 0 & 0 & 0 & -2.312\end{array}\right]^{\mathrm{T}}$} \\
\hline 2\# & {$\left[\begin{array}{llllll}-1 & 0 & 0 & 0 & 0 & 0\end{array}\right]^{\mathrm{T}}$} & & $2 \#$ & {$\left[\begin{array}{llllll}-2.595 & 0 & 0 & 0 & 0 & 0\end{array}\right]^{\mathrm{T}}$} & & $2 \#$ & {$\left[\begin{array}{llllll}-2.595 & 0 & 0 & 0 & 0 & -2.312\end{array}\right]^{\mathrm{T}}$} \\
\hline $3 \#$ & {$\left[\begin{array}{llllll}0 & -1 & 0 & 0 & 0 & 0\end{array}\right]^{\mathrm{T}}$} & \multirow{5}{*}{$F_{m c} \downarrow 1.595 \%$} & $3 \#$ & {$\left[\begin{array}{llllll}-1.595 & -1 & 0 & 0 & 0 & 0\end{array}\right]^{\mathrm{T}}$} & \multirow{5}{*}{$\mathrm{F}_{\eta p t} \downarrow-2.312 \%$} & 3\# & {$\left[\begin{array}{llllll}-1.595 & -1 & 0 & 0 & 0 & -2.312\end{array}\right]^{\mathrm{T}}$} \\
\hline $4 \#$ & {$\left[\begin{array}{llllll}0 & 0 & -1 & 0 & 0 & 0\end{array}\right]^{\mathrm{T}}$} & & $4 \#$ & 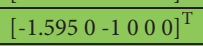 & & $4 \#$ & {$\left[\begin{array}{llllll}-1.595 & 0 & -1 & 0 & 0 & -2.312\end{array}\right]^{\mathrm{T}}$} \\
\hline $5 \#$ & {$\left[\begin{array}{lllllll}0 & 0 & 0 & -1 & 0 & 0\end{array}\right]^{\mathrm{T}}$} & & $5 \#$ & 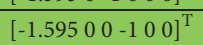 & & $5 \#$ & {$\left[\begin{array}{lllllll}-1.595 & 0 & 0 & -1 & 0 & -2.312\end{array}\right]^{\mathrm{T}}$} \\
\hline 6\# & {$\left[\begin{array}{lllllll}0 & 0 & 0 & 0 & -1 & 0\end{array}\right]^{\mathrm{T}}$} & & 6\# & {$\left[\begin{array}{llllll}-1.595 & 0 & 0 & 0 & -1 & 0\end{array}\right]^{\mathrm{T}}$} & & 6\# & {$\left[\begin{array}{lllllll}-1.595 & 0 & 0 & 0 & -1 & -2.312\end{array}\right]^{\mathrm{T}}$} \\
\hline $7 \#$ & {$\left[\begin{array}{lllllll}0 & 0 & 0 & 0 & 0 & -1\end{array}\right]^{\mathrm{T}}$} & & $7 \#$ & {$\left[\begin{array}{lllllll}-1.595 & 0 & 0 & 0 & 0 & -1\end{array}\right]^{\mathrm{T}}$} & & $7 \#$ & {$\left[\begin{array}{llllll}-1.595 & 0 & 0 & 0 & 0 & -3.312\end{array}\right]^{\mathrm{T}}$} \\
\hline
\end{tabular}

(b) Process of IMM-GLR based fault diagnosis in the scenarios of the $\mathrm{F}_{\mathrm{mc}}$ and the $\mathrm{F}_{\eta \mathrm{pt}}$ fault

FIGURE 8: Comparison of the diagnosis process between the IMM approach and the IMM-GLR approach in the scenarios of the $\mathrm{F}_{\mathrm{mc}}$ decreases $1.6 \%$ at $\mathrm{t}=5 \mathrm{~s}$ and the $\mathrm{F}_{\eta \mathrm{pt}}$ decreases $2.3 \%$ at $\mathrm{t}=15 \mathrm{~s}$.

approach, it can determine the location but cannot determine the severity of the fault. Therefore, in the process of diagnosing multiple faults, the change of fault severity in the new model set is artificially given. In Figure 8(a), the severity of the fault for each update of the model set is $-1 \%$, while the updated process is consistent with the IMM-GLR approach.

By comparing these two diagnosis processes, to diagnose the $\mathrm{F}_{\mathrm{mc}}$ fault and $\mathrm{F}_{\eta \mathrm{pt}}$ fault, the model set in the traditional IMM approach is updated four times, and there is no model in each update model set exactly which matches the actual fault. While the model set in the proposed IMM-GLR approach only needs to be updated twice, each updated model set has a model which exactly matches the actual fault. Therefore, the IMM-GLR approach can not only estimate the severity of the fault but also establish a more accurate model set to improve the detection and isolation performance of the IMM-based FDI algorithm.

To evaluate the performance of the IMM-GLR approach for multiple faults, the Monte-Carlo simulation analysis is also performed and compared with the traditional IMM approach. In this case, perform 100 simulations for two different faults and the severity of the each fault is in the interval $[-3 \%,-0.7 \%]$ and then analyzes the CDI, IFI, and MD for the multiple faults. The first fault occurs at $t=5 \mathrm{~s}$ and the second fault occurs at $t=15 \mathrm{~s}$. For each simulation, the IMM-GLR approach and the IMM approach are used to diagnose the fault at the same time, and the diagnosis process of multiple faults is referred to as the process shown in Figure 8.

Figure 9 shows the severity of the first fault and second fault in the 100 simulations, respectively. And it also shows the diagnosis results of the first fault and the second based on the
IMM-GLR approach and the IMM approach. In Figure 9, the CDI denotes that the fault is correctly detected and identified, the IFI denotes that the fault is incorrectly detected and identified and the MD denotes the fault is miss-detected. As shown in Figure 9, the proposed IMM-GLR approach significantly outperforms the IMM approach for multiple fault diagnosis.

Table 6 shows the comparison of the diagnosis results between the IMM-GRL approach and the IMM approach in the multiple fault scenarios. Due to the fact that IMM approach cannot determine the severity of the fault, it does not evaluate the estimation accuracy performance of the IMM. As shown in Table 6, for the IMM-GLR approach, whether it is the first fault or the second fault, besides one IFI, other faults are accurately diagnosed and the total CDI is 0.99. However, for the IMM approach, due to the fact that the models in the generated model set cannot match the actual fault very well, the CDI of the IMM approach is lower with the increase of the number of faults and total CDI is 0.27 .

Therefore, the IMM-GLR approach can improve the matching degree of the model in the model set and the actual fault condition by generating the model set based on the estimated fault severity and further improve the detection and isolation performance of the IMM-based FDI algorithm. In addition, from the value of the RMSE in Table 6, the GLR estimation approach can also accurately estimate the severity of the detected fault in the case of multiple faults.

\section{Conclusion}

In this paper, a IMM-GLR approach was proposed to detect, isolate, and estimate gas turbine abrupt gas path fault and 


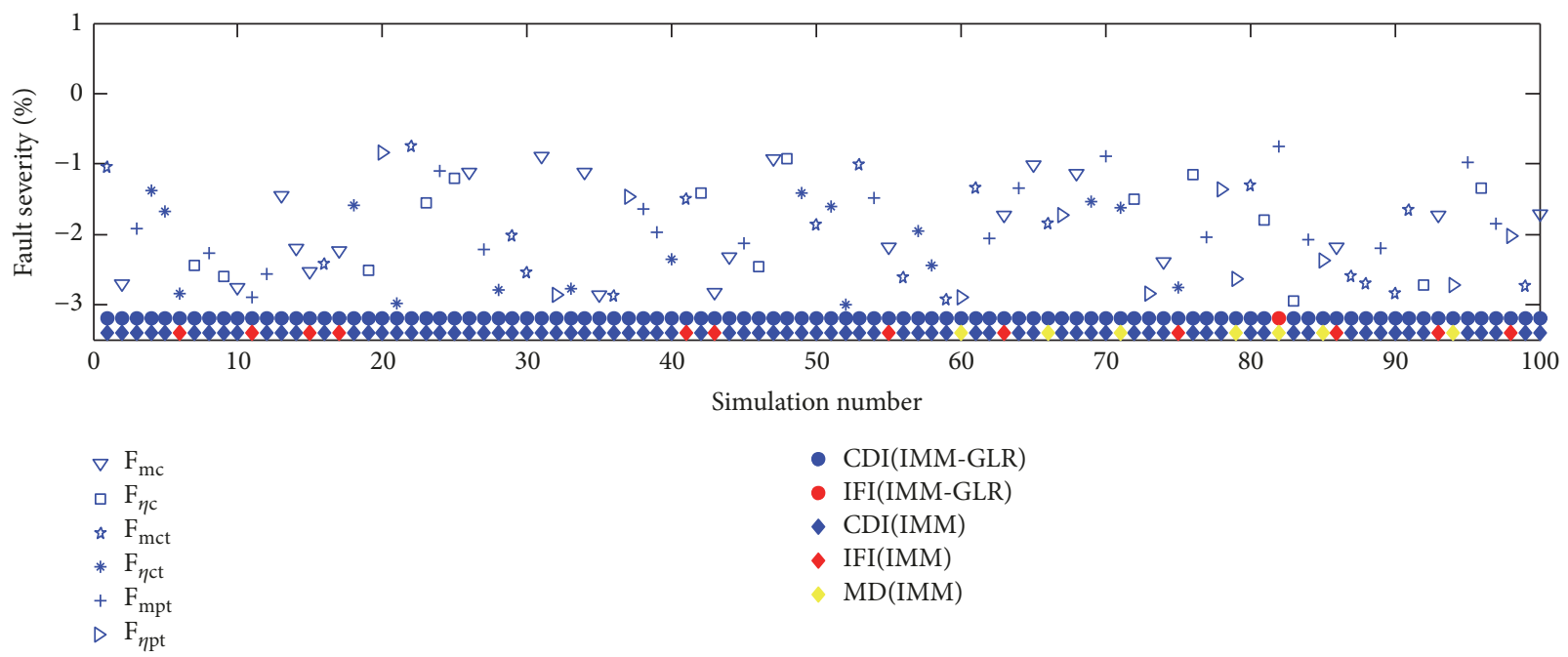

(a) First fault and diagnosis result

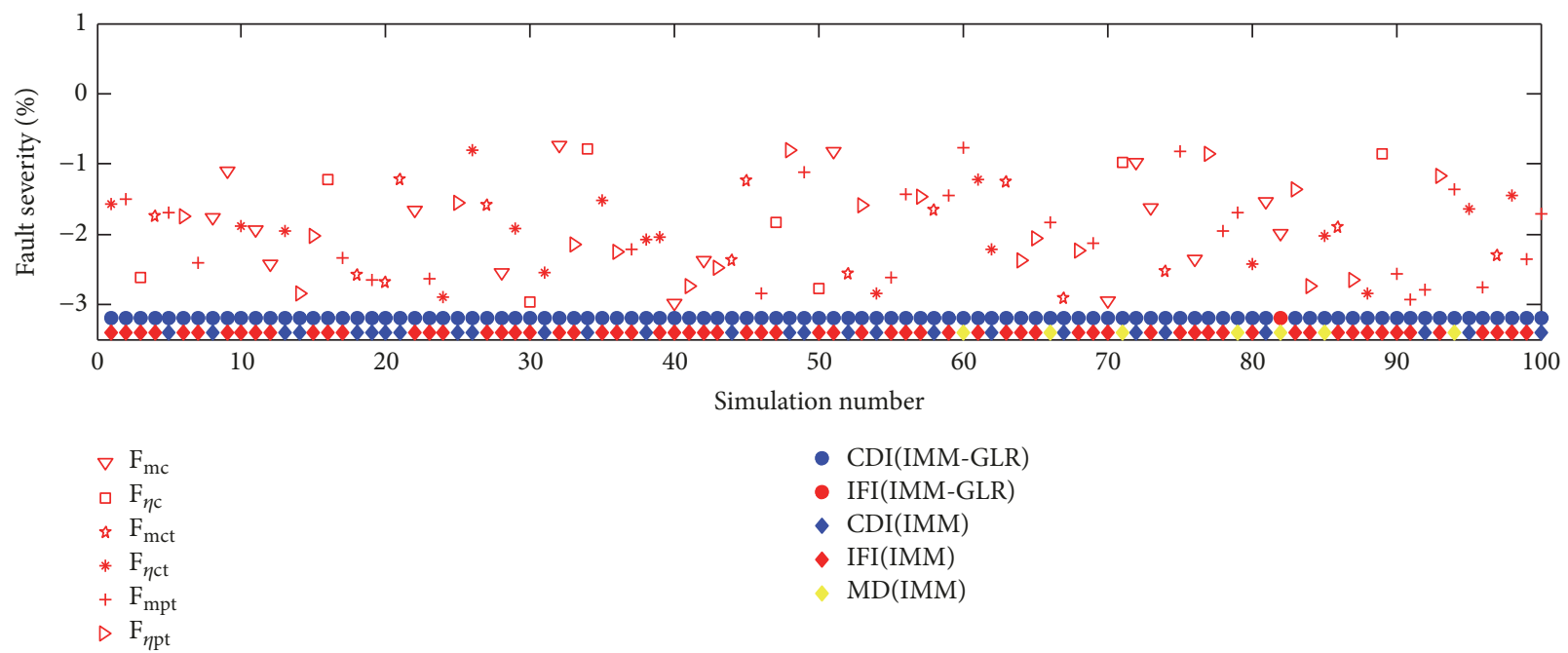

(b) Second fault and diagnosis result

FIGURE 9: Comparison of the diagnosis results between the IMM-GRL approach and the IMM approach in the multiple fault scenarios.

TABLE 6: Comparison of the diagnosis results between the IMM-GLR approach and the IMM approach in the multiple fault scenarios.

\begin{tabular}{lcc}
\hline Evaluate Parameters & IMM-GLR & IMM \\
\hline Total simulation & 100 & 100 \\
\hline CDI number of 1st fault & 99 & 81 \\
CDI number of 2nd Fault & 99 & 27 \\
Total CDI & 0.99 & 0.27 \\
\hline IFI number of 1st fault & 1 & 12 \\
IFI number of 2nd fault & 1 & 66 \\
Total IFI & 0.01 & 0.66 \\
\hline MD number of 1st fault & 0 & 7 \\
MD number of 2nd fault & 0 & 7 \\
Total MD & 0 & 0.07 \\
\hline RMSE & 0.026 & - \\
\hline
\end{tabular}


multiple gas path faults in the underdetermine estimation conditions. In this approach, the IMM-based FDI is used to detect and isolate the gas path fault and the GLR is used to estimate the severity of the detected fault. To evaluate the performance of the proposed approach, several case studies were conducted for a linear model of a marine gas turbine, and the results show that the IMM-GLR approach can not only detect and isolate single and multiple fault accurately but also accurately estimate the severity of the detected fault, and the estimated severity helps to establish a more accurate model set and can further improve the performance of the IMM-based FDI algorithm.

\section{Data Availability}

The data used to support the findings of this study are available from the corresponding author upon request.

\section{Conflicts of Interest}

The authors declare that they have no conflicts of interest.

\section{Acknowledgments}

This research is supported by the Fundamental Research Funds for the Central Universities (HEUCFP201722).

\section{References}

[1] A. J. Volponi, "Gas turbine engine health management: past, present and future trends," Journal of Engineering for Gas Turbines and Power, vol. 136, no. 5, Article ID 051201, pp. 433455, 2013.

[2] D. L. Simon and S. Garg, "Optimal Tuner Selection for Kalman Filter-Based Aircraft Engine Performance Estimation," Journal of Engineering for Gas Turbines and Power, vol. 132, no. 3, pp. 659-671, 2010.

[3] D. Simon, "A comparison of filtering approaches for aircraft engine health estimation," Aerospace Science and Technology, vol. 12, no. 4, pp. 276-284, 2008.

[4] S. S. Tayarani-Bathaie, Z. N. Sadough Vanini, and K. Khorasani, "Dynamic neural network-based fault diagnosis of gas turbine engines," Neurocomputing, vol. 125, no. 3, pp. 153-165, 2014.

[5] N. Meskin, "Multiple-model sensor and components fault diagnosis in gas turbine engines using autoassociative neural networks," Journal of Engineering for Gas Turbines \& Power, vol. 136, no. 9, Article ID 091603, 2014.

[6] F. Anguel and M. Sellami, "Knowledge Management for Fault Diagnosis of Gas Turbines Using Case Based Reasoning," Communications of the IBIMA, pp. 10-24, 2009.

[7] R. Barbosa and S. Ferreira, "Industrial Gas Turbine Diagnostics Using Fuzzy Logic," in Proceedings of the ASME Turbo Expo 2012: Turbine Technical Conference and Exposition, pp. 207-218, Copenhagen, Denmark, 2012.

[8] Y. G. Li, "Performance-analysis-based gas turbine diagnostics: A review," Proceedings of the Institution of Mechanical Engineers, Part A: Journal of Power and Energy, vol. 216, no. 5, pp. 363-377, 2002.

[9] L. Marinai, D. Probert, and R. Singh, "Prospects for aero gasturbine diagnostics: A review," Applied Energy, vol. 79, no. 1, pp. 109-126, 2004.
[10] C. Kong, "Review on advanced health monitoring methods for aero gas turbines using model based methods and artificial intelligent methods," International Journal of Aeronautical and Space Sciences, vol. 15, no. 2, pp. 123-137, 2014.

[11] X. Pu, S. Liu, H. Jiang, and D. Yu, "Adaptive gas path diagnostics using strong tracking filter," Proceedings of the Institution of Mechanical Engineers, Part G: Journal of Aerospace Engineering, vol. 228, no. 4, pp. 577-585, 2014.

[12] Y. Ying, Y. Cao, S. Li, and J. Li, "Nonlinear Steady-State Model Based Gas Turbine Health Status Estimation Approach with Improved Particle Swarm Optimization Algorithm," Mathematical Problems in Engineering, vol. 2015, Article ID 940757, 12 pages, 2015.

[13] M. D. Espańa, "On the estimation algorithm for adaptive performance optimization of turbofan engines," Chi Ea Chi Extended Abstracts on Human Factors in Computing Systems, vol. 24, no. 1, pp. 1189-1190, 1993.

[14] N. Meskin, E. Naderi, and K. Khorasani, "A multiple modelbased approach for fault diagnosis of jet engines," IEEE Transactions on Control Systems Technology, vol. 21, no. 1, pp. 254-262, 2013.

[15] D. T. Magill, "Optimal Adaptive Estimation of Sampled Stochastic Processes," IEEE Transactions on Automatic Control, vol. 10, no. 4, pp. 434-439, 1965.

[16] P. D. Hanlon and P. S. Maybeck, "Multiple-model adaptive estimation using a residual correlation Kalman filter bank," IEEE Transactions on Aerospace and Electronic Systems, vol. 36, no. 2, pp. 393-406, 2000.

[17] Y. Zhang and X. R. Li, "Detection and diagnosis of sensor and actuator failures using IMM estimator," IEEE Transactions on Aerospace and Electronic Systems, vol. 34, no. 4, pp. 1293-1313, 2002.

[18] J. Ru and X. R. Li, "Variable-structure multiple-model approach to fault detection, identification, and estimation," IEEE Transactions on Control Systems Technology, vol.16, no. 5, pp. 1029-1038, 2008.

[19] E. Naderi, N. Meskin, and K. Khorasani, "Nonlinear fault diagnosis of jet engines by using a multiple model-based approach," Journal of Engineering for Gas Turbines and Power, vol. 134, no. 1, pp. 63-75, 2011.

[20] Q. Yang, S. Li, and Y. Cao, "A strong tracking filter based multiple model approach for gas turbine fault diagnosis," Journal of Mechanical Science and Technology, vol. 32, no. 1, pp. 465-479, 2018.

[21] H. H. Lambert, A Simulation Study of Turbofan Engine Deterioration Estimation Using Kalman Filtering Techniques, 1991.

[22] A. S. Willsky and H. L. Jones, "A Generalized Likelihood Ratio Approach to the Detection and Estimation of Jumps in Linear Systems," IEEE Transactions on Automatic Control, vol. 21, no. 1, pp. 108-112, 1976.

[23] J. Prakash, S. C. P. Patwardhan, and S. Narasimhan, "A supervisory approach to fault-tolerant control of linear multivariable systems," Industrial \& Engineering Chemistry Research, vol. 41, no. 9, pp. 2270-2281, 2002.

[24] A. P. Deshpande and S. C. Patwardhan, "Online fault diagnosis in nonlinear systems using the multiple operating regime approach," Industrial \& Engineering Chemistry Research, vol. 47, no. 17 , pp. 6711-6726, 2008. 


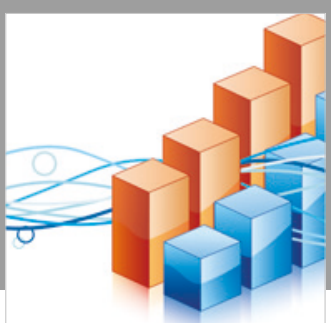

Advances in

Operations Research

\section{-n-m}
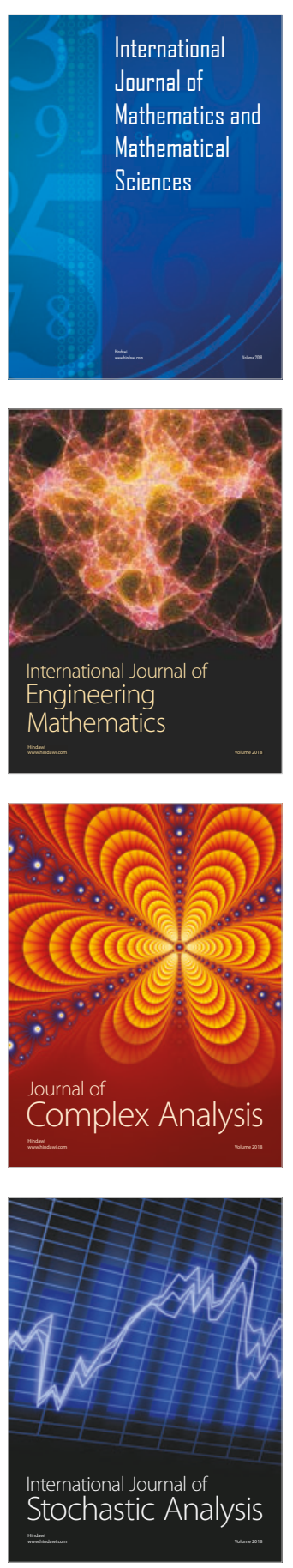
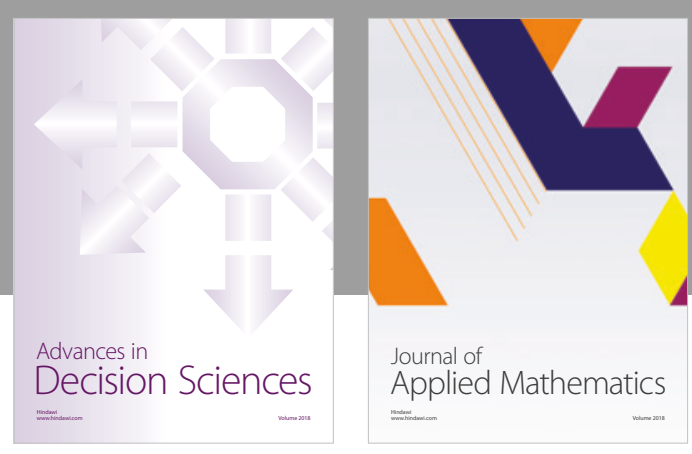

Journal of

Applied Mathematics
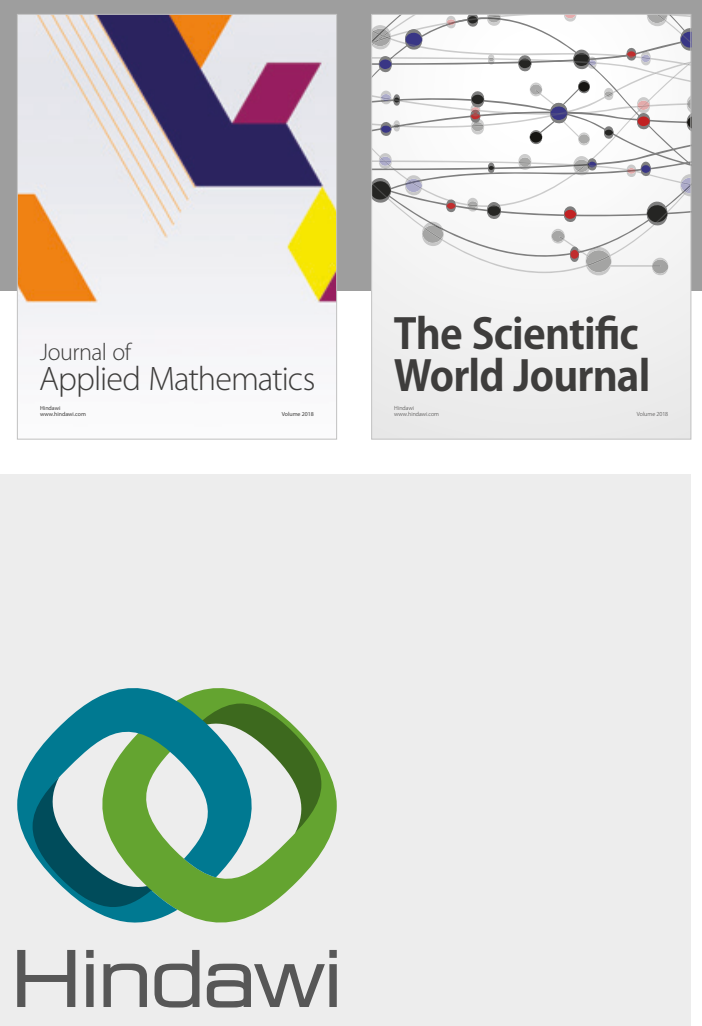

Submit your manuscripts at

www.hindawi.com

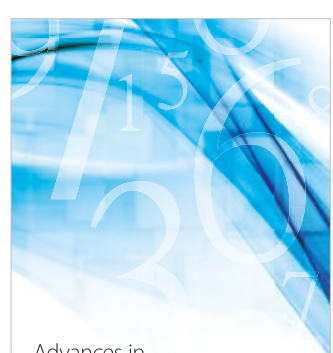

Advances in
Numerical Analysis
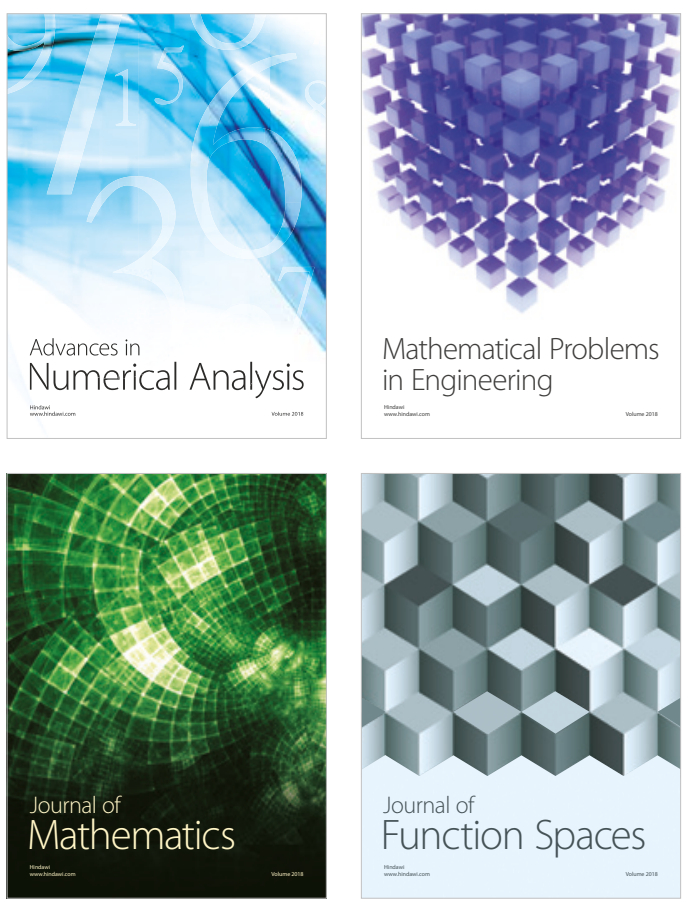

Mathematical Problems in Engineering

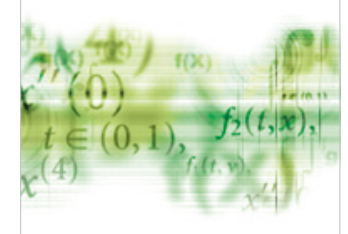

International Journal of

Differential Equations

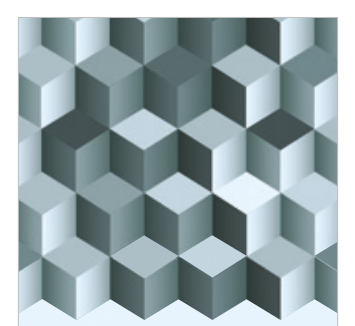

Journal of

Function Spaces

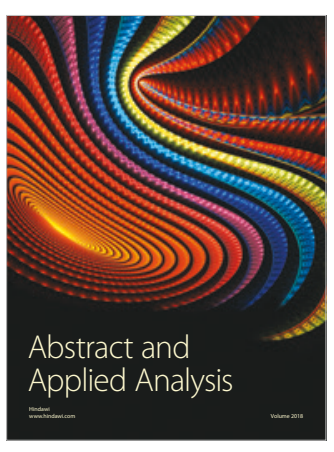

The Scientific

World Journal

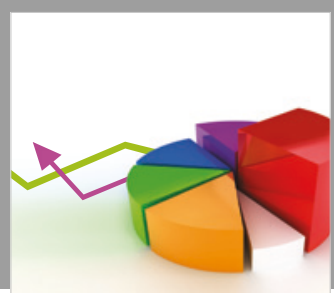

Journal of

Probability and Statistics
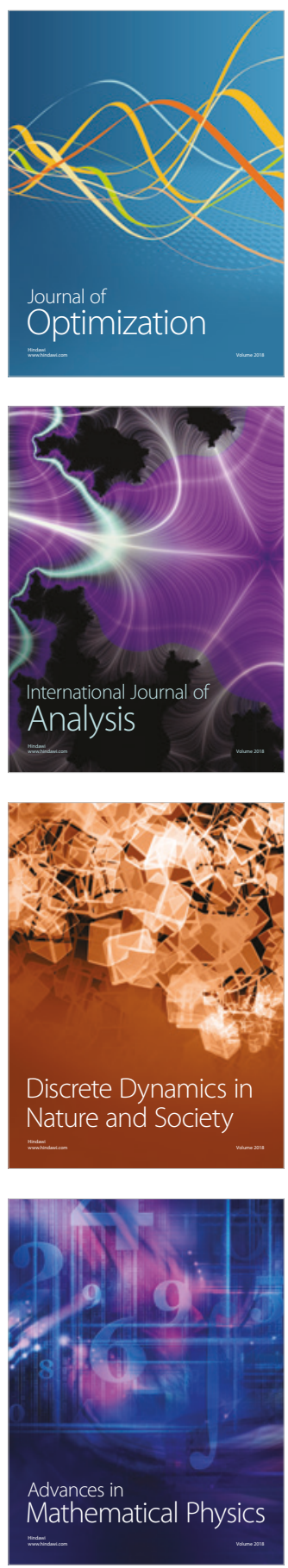